\title{
PERAMALAN NILAI EKSPOR DI PROVINSI SUMATERA BARAT DENGAN METODE ARIMA (AUTOREGRESSIVE INTEGRATED MOVING AVERAGE)
}

\author{
YESSI OKTREZA, HAZMIRA YOZZA, MAIYASTRI \\ Program Studi Matematika, \\ Fakultas Matematika dan Ilmu Pengetahuan Alam, Universitas Andalas, \\ Kampus UNAND Limau Manis Padang, Indonesia, \\ email : yessioktreza@gmail.com
}

\begin{abstract}
Abstrak. Ekspor merupakan penjualan suatu komoditi pada orang asing, bangsa asing dan negara asing. Nilai ekspor mengacu pada nilai FOB. Nilai Ekspor di Sumatera Barat mempunyai pengaruh cukup besar terhadap perekonomian Indonesia karena semakin banyak ekspor maka semakin besar devisa yang diperoleh Negara. Penelitian ini bertujuan untuk memodelkan nilai ekspor di provinsi Sumatera Barat. Metode peramalan yang digunakan adalah ARIMA (Autoregressive Integrated Moving Average). Adapun data yang digunakan adalah nilai ekspor di provinsi Sumatera Barat periode tahun 2010-2015. Model peramalan yang diperoleh adalah model ARIMA(3,10).
\end{abstract}

Kata Kunci: Deret Waktu, ARIMA, Nilai Ekspor

\section{Pendahuluan}

Perdagangan internasional ekspor impor merupakan kegiatan transaksi jual beli suatu komoditi dengan orang asing, bangsa asing, dan negara asing [1]. Menurut Badan Pusat Stasistik, nilai ekspor mengacu pada nilai FOB (Free On Board) yaitu biaya pengiriman suatu komoditi sampai pelabuhan terdekat dari gudangnya. Nilai FOB dalam bentuk dollar Amerika. Badan Pusat Statistik mencatat bahwa nilai ekspor Sumatera Barat periode 2012-2015 selalu mengalami penurunan. Oleh karena itu, perlu dilakukan suatu peramalan (forecasting) nilai ekspor dimasa akan datang, agar pemerintah Sumatera Barat tepat dalam pengambilan kebijakan dengan metode ARIMA menggunakan software Eviews 8.

Pada tulisan ini akan dibahas tentang bagaimana model ARIMA yang baik ntuk memodelkan dan memprediksi atau meramalkan nilai ekspor Sumatera Barat dengan menggunakan data bulanan nilai ekspor Sumatera Barat periode tahun 2010-2015.

\section{Tinjauan Pustaka}

\subsection{Ekspor}

Nilai ekspor mengacu pada nilai FOB. Dengan adanya ekspor, pemerintah memperoleh pendapatan berupa devisa, semakin banyak ekspor semakin besar devisa 
yang diperoleh negara.

\subsection{Pengertian dan Jenis-Jenis Peramalan}

Peramalan adalah perkiraan tentang sesuatu yang akan terjadi pada waktu yang akan datang berdasarkan pada data yang ada waktu sekarang dan waktu lampau. Dilihat dari sifat ramalan yang telah disusun, maka peramalan dapat dibedakan atas dua macam, yaitumetode peramalan kuantitatif dan kualitatif. Salah satu metode peramalan kuantitatif adalah metode deret waktu (time series). Dataderet waktu adalah sekumpulan data pengamatan yang diperoleh dari perhitungan dari waktu ke waktu.

\subsection{Pola Data}

Pola data terbagi atas empat macam, yaitu Pola Horizontal (pola data stasioner), Pola Trend, Pola Musiman dan Pola Siklis.

\subsection{Kestasioneran}

Data bersifat stasioner pada nilai tengah apabila data tersebut berfluktuasi di sekitar nilai tengah yang konstan sepanjang waktu pengamatan. Jika data tidak stasioner terhadap nilai tengah maka dilakukan pembedaan. Data bersifat stasioner terhadap ragam adalah apabila data berfluktuasi dengan ragam yang konstan dari waktu ke waktu. Jika data tidak stasioner terhadap ragam, maka dilakukan transformasi Box-Cox plot.

\subsection{Model-Model Deret Waktu}

Misalkan $X_{t}$ adalah data deret waktu dan $\mu=E\left(X_{t}\right)$. Fungsi kovarians dari $X_{t}$ adalah

$$
\gamma(t, t+k)=\operatorname{Cov}\left(X_{t}, X_{t+k}\right)
$$

Partial Autocorrelation Function (PACF) untuk sampel $X_{1}, X_{2}, X_{3}, \cdots, X_{n}$ dengan $X_{i} X_{j}$ untuk setiap i dan j dinyatakan

$$
\hat{\Phi}_{k}=\hat{\Gamma}_{k}^{-1} \hat{\gamma}_{k}
$$

sedangkan ACF untuk data sampel adalah

$$
\hat{\rho}_{k}=\hat{\gamma}_{k} / \hat{\gamma}_{0}=\operatorname{Corr}\left(X_{t}, X_{t+k}\right)
$$

Jika $X_{t}$ adalah deret dari peubah acak yang tidak saling berkorelasi dan berdistribusi normal yang mempunyai nilai tengah nol dan ragam konstan, maka deret ini dinamakan white noise yang dinotasikan

$$
X_{t} \sim W N\left(0, \sigma^{2}\right)
$$


2.5.1. Model Autoregressive $(A R)$

Bentuk umum dari model $A R(p)$ adalah:

$$
X_{t}=\Phi_{1} X_{t-1}+\Phi_{2} X_{t-2}+\cdots+\Phi_{p} X_{t-p}+\varepsilon_{t},
$$

dengan $X_{t}$ adalah nilai X periode ke-t, $\Phi_{p}$ adalah parameter AR ke-p, dan $\varepsilon_{t}$ adalah error (kesalahan) pada periode ke-t, $\varepsilon_{t} \sim W N\left(0, \sigma^{2}\right)$.

\subsubsection{Model Moving Average (MA)}

Bentuk umum dari model MA(q) adalah :

$$
X_{t}=\varepsilon_{t}+\Theta_{1} \varepsilon_{t-1}+\cdots+\Theta_{p} \varepsilon_{t-p}+\varepsilon_{t},
$$

dengan $\Theta_{i}$ parameter MA ke-i dengan $i=1,2, \cdots, q$.

\subsubsection{Model Autoregressive Moving Average (ARMA)}

Bentuk umum dari model $\operatorname{ARMA}(\mathrm{p}, \mathrm{q})$ adalah :

$$
X_{t}=\Phi_{1} X_{t-1}+\Phi_{2} X_{t-2}+\cdots+\Phi_{p} X_{t-p}-\varepsilon_{t}-\Theta_{1} \varepsilon_{t-1}-\cdots-\Theta_{p} \varepsilon_{t-p}-\varepsilon_{t} .
$$

\subsubsection{Model Autoregressive Integrated Moving Average (ARIMA)}

Bentuk umum model $A R I M A(p, d, q)$ dengan $p$ menunjukkan orde AR, $d$ menunjukkan orde pembedaan dan $q$ menunjukkan orde MA ditulis sebagai berikut :

$X_{t}=\nabla^{d} \Phi_{1} X_{t-1}+\nabla^{d} \Phi_{2} X_{t-2}+\cdots+\nabla^{d} \Phi_{p} X_{t-p}+\nabla^{d} \varepsilon_{t}-\nabla^{d} \Theta_{1} \varepsilon_{t-1}-\cdots-\nabla^{d} \Theta_{p} \varepsilon_{t-p}-\nabla^{d} \varepsilon_{t}$.

Identifikasi model merupakan tahap penentuan apakah model yang terbentuk

\begin{tabular}{|c|c|c|}
\hline Model & $\overline{A C F}$ & PACF \\
\hline $\operatorname{AR}(p)$ & $\begin{array}{l}\text { Alenunom secara elspocensial atau } \\
\text { mengihat gelombang sinus }\end{array}$ & Tenpotong pada lag ke:p \\
\hline $\mathrm{MA}(q)$ & Tenpotong pada lag ke-q & $\begin{array}{l}\text { Merunom secara elspocoensial atau } \\
\text { mengihati gelombang sinus }\end{array}$ \\
\hline ARVA(DQS) & $\begin{array}{l}\text { Menunom secara elsponensial atau } \\
\text { mengihati gelombang sinus }\end{array}$ & $\begin{array}{l}\text { Merunom secara elsponensial atau } \\
\text { mengihati gelombang simus }\end{array}$ \\
\hline
\end{tabular}
adalah model $A R(p), M A(q)$ atau $A R M A(p, q)$, sebagaimana yang terlihat pada Tabel 1.

Tabel 1. Penentuan Model dengan Plot ACF dan PACF 


\subsubsection{Pemilihan Model Terbaik}

Model terbaik yang dapat digunakan untuk peramalan adalah model dengan nilai AIC (Akaike Information Criterion), BIC (Bayesian Information Criterion), dan HQ (Hannan and Quinn Criterion) terkecil.

\subsubsection{Pemeriksaan Diagnosa (Diagnostic Checking)}

Setelah melakukan pemilihan model terbaik selanjutnya dilakukan uji asumsi sisaan dari model tersebut diantaranya uji autokorelasi sisaan, uji heterokedastisitas sisaan, dan uji normalitas sisaan. Jika correlogram sisaan model menunjukkan nilai probabilitas lebih besar dari taraf signifikan $\alpha=0.5$ pada tiap lagmaka sisaan tidak mempunyai autokerelasi sisaan. Jika nilai-Prob pada correlogram of residual squared besar dari taraf signifikan pada tiaplag maka variansi sisaan tidak konstan artinya sisaan tidak bersifat heterokedastisitas. Model dikatakan baik jika residualnya berdistribusi secara normal. Salah satu uji yang dapat dilakukan adalah uji Jarque Bera dengan statistik uji

$$
J B=\frac{n}{6}\left(S^{2}+\frac{(K-3)^{2}}{4}\right) .
$$

Model berdistribusi normal jika nilai JB lebih kecil dari $\chi_{(t a b e l)}^{2}$, dengan $\alpha=$ 0,$05 ; d f=2$.

\section{Hasil dan Pembahasan}

\subsection{Plot Data}

Dalam hal ini plot data nilai ekspor di Sumatera Barat berguna untuk melihat apakah data sudah stasioner dalam nilai tengah dan ragam.
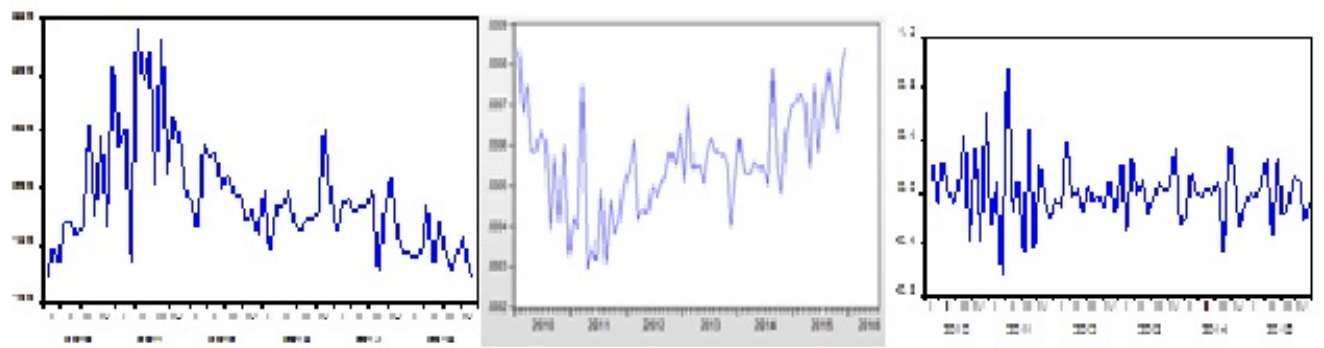

Gambar 1. (a) Grafik Data Nilai Ekspor di Sumatera Barat, (b) Grafik Data Nilai Ekspor di Sumatera Barat Hasil Transformasi, (c) Grafik Data Nilai Ekspor di Sumatera Barat Hasil Transformasi dan Pembedaan

Dari Gambar 1(a) di atas dengan sumbu-X adalah periode dalam bulan dan sumbu-Y adalah nilai ekspor dalan juta Dollar Amerika terlihat bahwa sebaran data tidak terfokus disekitar nilai tengah dan ragam dari data tidak konstan. Hal tersebut diperkuat dengan nilai statistik uji ADF lebih besar dari nilai kritis pada 
$=0,05$ yang berarti data nilai ekspor di Sumatera Barat belum stasioner dalam nilai tengah. Data distasionerkan terhadap ragam dengan menggunakan Transformasi Box-Cox plot $1 / X_{t}$.

Pada Gambar 1(b) dengan sumbu-X adalah periode dalam bulan dan sumbuY adalah nilai ekspor setelah ditransformasi, dalam juta Dollar Amerika terlihat bahwa nilai ekspor hasil transformasi tidak konstan sedangkan ragam bernilai konstan. Hal ini diperkuat dengan rounded value $(\lambda)$ yang dihasilkan setelah dilakukan transformasi sebesar 1,00, sehingga disimpulkan bahwa data nilai ekspor di Sumatera Barat setelah ditransformasikan stasioner terhadap ragam. Karena data belum stasioner terhadap nilai tengah, maka dilakukan pembedaan pertama.

Dari hasil plot pada Gambar 1(c) terlihatdata setelah transformasi dan pembedaan pertama telah berada dalam keadaan stasioner. Hal ini diperkuat dengan nilai uji ADFdata setelah dilakukan transformasi dan pembedaanlebih kecil dari nilai kritis pada $\alpha=0,05$ yang berarti data nilai ekspor di Sumatera Barat telah stasioner terhadap nilai tengah.

\subsection{Identifikasi Model ARIMA}

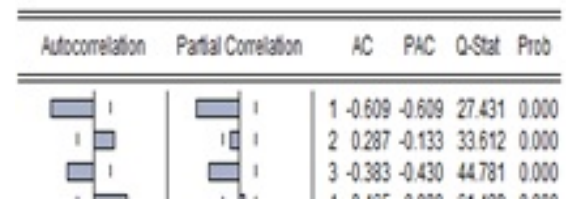

Gambar 2. Correlogram ACF dan PACF

Dari Gambar 2 terlihat bahwa ACF menurun secara eksponensial dari lag ke-1 dan pada PACF ( terpotong) pada lag ke-1 dan ke-3, sehingga diperoleh semua kemungkinan model $\operatorname{ARIMA}(p, 1, q)$ adalah $\operatorname{ARIMA}(3,1,0), \operatorname{ARIMA}(1,1,0)$.

\subsection{Estimasi Model ARIMA}

Setelah diperoleh model yang diperkirakan cocok dengan data, langkah selanjutnya adalah melakukan estimasi parameter model dan pengujian signifikansi parameter.

\begin{tabular}{|c|cc|c|c|}
\hline Model & \multicolumn{2}{|c|}{ Parameter } & Koefisien & Nilai-p \\
\hline ARIMA(3,1,0) & Koefisien AR: & $\boldsymbol{O}_{1}$ & $-0,765664$ & 0,0000 \\
& & $\boldsymbol{O}_{2}$ & $-0,509989$ & 0,0004 \\
& & $\boldsymbol{O}_{3}$ & $-0,421815$ & 0,0004 \\
\hline ARIMA(1,1,0) & koefisien AR: & $\boldsymbol{O}_{1}$ & $-0,563098$ & 0,0000 \\
\hline
\end{tabular}

Tabel 2. Estimasi Parameter Model $\operatorname{ARIMA}(p, 1, q)$ 
Berdasarkan Tabel 2 terlihat bahwa pada parameter model $\operatorname{ARIMA}(3,1,0)$ dan $\operatorname{ARIMA}(1,1,0)$ diperoleh nilai probability (Nilai-p) lebih kecil dari taraf signifikan $\alpha=0,05$ maka dapat disimpulkan bahwa model $\operatorname{ARIMA}(3,1,0)$, dan $\operatorname{ARIMA}(1,1,0)$ layak dimasukkan kedalam model $\operatorname{ARIMA}(p, 1, q)$.

\subsection{Pemilihan Model Terbaik}

Berdasarkan estimasi parameter, diperoleh model $\operatorname{ARIMA}(3,1,0)$ mempunyai nilai AIC, BIC dan HQ yang paling kecil dibandingkan dengan model lainnya yaitu $-10,94348,-10,84556,-10,90468$ sehingga disimpulkan bahwa model $\operatorname{ARIMA}(3,1,0)$ adalah model terbaik untuk data nilai ekspor di Sumatera Barat. Berdasarkan nilai koefisien parameter model ARIMA $(3,1,0)$ pada Tabel 2 diperoleh persamaan untuk data nilai ekspor di Sumatera Barat dituliskan sebagai berikut

$$
\nabla^{1} \frac{1}{X_{t}}=-0,765664 \nabla^{1} \frac{1}{X_{t-1}} 0,509989 \nabla^{1} \frac{1}{X_{t-2}} 0,421815 \nabla^{1} \frac{1}{X_{t-3}}+\varepsilon_{t} .
$$

\subsection{Pemeriksaan Diagnosa}

Selanjutnya, dilakukan diagnostic checking terhadap sisaan untuk model yang terpilih sebagai model yang terbaik. Berdasarkan correlogram sisaan model $\operatorname{ARIMA}(3,1,0)$ diperoleh plot ACF dan PACF yang signifikan (nilai probabilitas lebih besar dari taraf signifikan $\alpha=0.5$ ) pada tiap lag maka sisaan tidak mempunyai autokorelasi.

Berdasarkan correlogram kuadrat sisaan model $\operatorname{ARIMA}(3,10)$ diperoleh semua nilai-Probdari model $\operatorname{ARIMA}(3,1,0)$ lebih besar dari $\alpha=0,05$, ini berarti sisaan model ARIMA $(3,1,0)$ tidak bersifat heterokedastisitas serta berdasarkan histogram uji normalitas sisaan diperoleh nilai JarqueBera $(J B)$ lebih kecil dari $\chi_{(\text {tabel })}^{2}(\alpha=$ $0,05 ; d f=2)=5,991$ artinya sisaan model $\operatorname{ARIMA}(3,1,0)$ menyebar normal.

\subsection{Peramalan}

Model ARIMA(3,1,0) adalah model terbaik, maka model tersebut dapat digunakan untuk meramalkan nilai ekspor periode Januari 2016 sampai dengan Juni 2016 yang disajikan dalam Tabel 3 berikut.

\begin{tabular}{|l|l|c|l|}
\hline $\begin{array}{l}\text { Periode } \\
2016\end{array}$ & $\begin{array}{l}\text { Aktual }\left(X_{1}\right) \\
\text { (juta dollar Amerika) }\end{array}$ & $\begin{array}{l}\text { Peramalan }(F) \\
\text { (iuta dollar Amerika) }\end{array}$ & $\begin{array}{l}\text { Errori } \\
\text { (juta dollar Amerika) }\end{array}$ \\
\hline Januari & 98,20000 & 133,4147 & 35,2147 \\
\hline Februari & 120,9000 & 137,3940 & 16,4940 \\
\hline Maret & 119,4000 & 130,0594 & 10,6594 \\
\hline April & 121,5000 & 130,0594 & 8,5594 \\
\hline Mei & 154,1000 & 131,3166 & 22,7834 \\
\hline Juni & 118,0000 & 132,5105 & 14,5105 \\
\hline
\end{tabular}

Tabel 3. Perbandingan Hasil Peramalan dengan Data Aktual 
22 Yessi Oktreza dkk.

\section{Daftar Pustaka}

[1] Amir, MS. 2001. Ekspor Impor. PT Pustaka Binaman Presindo, Jakarta.

[2] Assauri, S. 1984. Teknik dan Metode Peramalan. Edisi 1. Lembaga Penerbit Fakultas Ekonomi Universitas Indonesia, Jakarta.

[3] Brockwell, P. J., R. A. Davis. 2002. Introduction to Time Series and Forecasting. Springer, New York.

[4] Gujarati. 2004. Basic Econometrics. Fourth Edition. The McGraw-Hill Companies. 